This PDF is a selection from a published volume from the National Bureau of Economic Research

Volume Title: African Successes, Volume II: Human Capital

Volume Author/Editor: Sebastian Edwards, Simon Johnson, and David N. Weil, editors

Volume Publisher: University of Chicago Press

Volume ISBNs: 978-0-226-31605-5 (cloth)

Volume URL: http://www.nber.org/books/afri14-2

Conference Dates: December 11-12, 2009; July 18-20, 2010; August 3-5, 2011

Publication Date: September 2016

Chapter Title: Stimulating Demand for AIDS Prevention: Lessons from the RESPECT Trial

Chapter Author(s): Damien de Walque, William H. Dow, Carol Medlin, Rose Nathan

Chapter URL: http://www.nber.org/chapters/c13375

Chapter pages in book: (p. $85-112$ ) 


\title{
Stimulating Demand for AIDS Prevention Lessons from the RESPECT Trial
}

\author{
Damien de Walque, William H. Dow, Carol Medlin, and \\ Rose Nathan
}

\subsection{Introduction}

Conventional approaches to HIV prevention have been important in educating populations about HIV risk factors and risk-reduction strategies, and many have been found to be cost effective, but by themselves they have had limited success in slowing the AIDS epidemic. Over the past decade the annual number of new infections has decreased by about one-fifth, but in 2009 there were still an estimated 2.6 million new HIV infections, and 1.8 million of these were in sub-Saharan Africa (UNAIDS 2010). HIV experts have highlighted the need for new combination approaches to complement existing prevention efforts (Coates, Richter, and Caceres 2008; Padian et al. 2011), including efforts to stimulate individual demand for prevention.

Damien de Walque is a senior economist in the Development Research Group (Human Development and Public Services Team) at the World Bank. William H. Dow is the Henry J. Kaiser Professor of Health Economics at the University of California, Berkeley, and a research associate of the National Bureau of Economic Research. Carol Medlin is a director of health at the Children's Investment Fund Foundation (CIFF). Rose Nathan is a senior research scientist at the Ifakara Health Institute.

We have benefited greatly from the insights and efforts of the RESPECT Project Team and many others who contributed to the intellectual development and success of the RESPECT project. We are also grateful to Adam Wagstaff for useful comments. We acknowledge funding support for this chapter from the NBER Africa Project, and support for the overall RESPECT project from the William and Flora Hewlett Foundation (through the Population Reference Bureau), the World Bank Research Committee, and the Spanish Impact Evaluation Fund and the Knowledge for Change Program (KCP) managed by the World Bank. The findings, interpretations, and conclusions expressed in this chapter are entirely those of the authors, and do not represent the views of any of the authors' institutions or funders. For acknowledgments, sources of research support, and disclosure of the authors' material financial relationships, if any, please see http://www.nber.org/chapters/c13375.ack. 
This chapter considers the use of economic incentives to encourage people to engage in behavioral change strategies that reduce risky sexual behaviors. Incentives have been widely used in a variety of related domains, but are only recently being explored as a possible HIV prevention strategy. One type of widely adopted incentive scheme in the health domain is as part of conditional cash transfer (CCT) programs such as the wellknown Oportunidades program in Mexico, which provides significant cash welfare support to households that engage in specific positive behaviors, including appropriate prenatal and well-child care. Lagarde, Haines, and Palmer (2007) and Fiszbein and Schady (2009) survey such programs in detail. Related programs are being explored in the sub-Saharan African context, but with conditionality focused on nonhealth behaviors such as schooling (which can then indirectly yield positive health consequences, e.g., Baird et al. [2010], [2012]). There is also a history of providing positive price incentives for using specific types of preventive health services, most relevant in this context being the use of cash incentives to promote receipt of HIV test results (Thornton 2008). The aforementioned incentive programs are all conditioned on observable input behaviors, which can be controlled by participants. A parallel set of "contingency management" programs have been designed for situations in which behavior changes are more complex and/or not easily observed, and in which conditionality is instead based on outcomes. This contingency management approach has been most widely adopted in the substance abuse field, for example, providing rewards to substance abuse treatment patients if they are negative on random drug tests; such programs have been found in developed country contexts to be feasible, acceptable, and effective (Stitzer 2006).

In this chapter we discuss a variant of the above incentive programs, using outcome-based incentives adapted to the sexual domain (possibly within the context of a larger CCT program). After reviewing traditional HIV-prevention strategies as well as what is known from prior literature on incentives in the types of contexts discussed above (drawn partly from Medlin and de Walque [2008]), we discuss the theoretical pathways by which incentive programs could work to reduce risky sexual behavior. We then turn to a specific example in detail, elaborating on one such project in Tanzania (the RESPECT project, of which the authors are the principal investigators), which has implemented a novel randomized trial of outcomebased incentives to reduce risky sexual behavior. ${ }^{1}$ The RESPECT project was a one-year intervention in which participants were tested for curable

1. We are only aware of one other study that has attempted to similarly incent outcomes associated with risky sexual behaviors. Kohler and Thornton (2011) report on a trial in Malawi in which HIV-negative individuals were randomized to cash reward levels to be paid one year later conditional on remaining HIV negative. In contrast to the RESPECT study, which found significant reductions in STIs, the Malawi study found null results on HIV conversion (the main measured outcome), although there was low power to detect HIV changes in that study. 


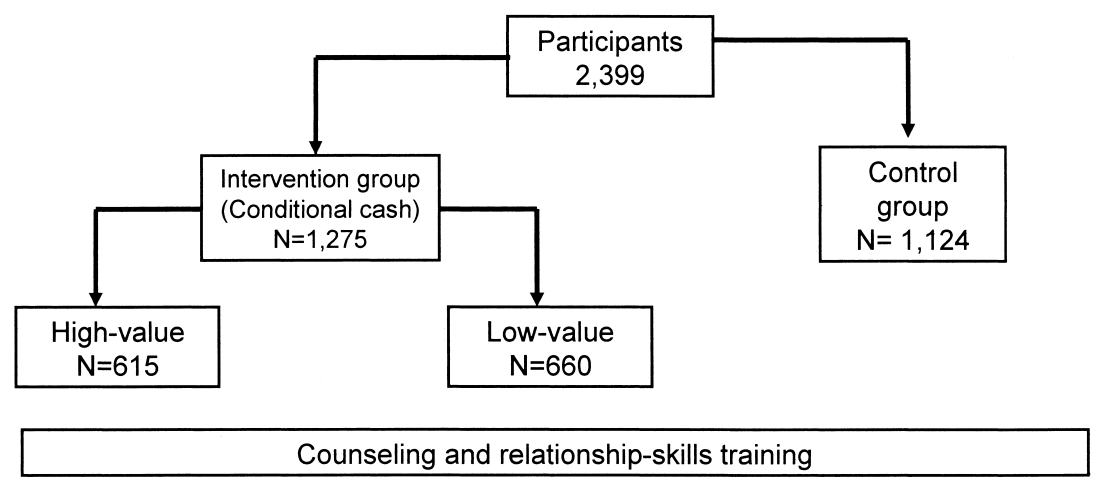

Fig. 3.1 The RESPECT randomized study design

sexually transmitted infections (STIs) at four-month intervals, and received cash rewards if STI negative. The results from the impact evaluation of this intervention are reported in de Walque et al. (2012). Figure 3.1 presents the basic randomized design of the RESPECT study's 2,399 participants across two treatments arms (with different levels of cash rewards) and a control arm. The balance of the chapter focuses on lessons learned from the RESPECT trial and implications for such efforts in the future.

\subsection{Traditional Approaches to HIV Prevention}

The social, economic, and human costs of the AIDS epidemic in subSaharan Africa are staggering (Eiss and Glass 2007), and innovative solutions to stem the tide of the epidemic are desperately needed. Globally, an estimated 33 million people were living with HIV in 2009. That same year, an estimated 1.8 million people lost their lives to AIDS, and an estimated 2.6 million became newly infected. The global epicenter of the AIDS pandemic is in Africa, where an estimated 22.5 million people were living with HIV in 2009 including approximately 5 percent of adults, and an estimated 1.8 million new infections occurred during that year (UNAIDS 2010). Young people, ages fifteen to twenty-five, are at particularly high risk of new infection.

The tragic reality is that many of these new infections could have been prevented. At its core, the global AIDS epidemic is fueled by risky sexual behavior. Over 80 percent of HIV infections occur through sexual contact with an infected partner (Askew and Berer 2003), and could have been avoided through the adoption of safer sexual behaviors including condom use, reduction in the number and concurrency of sexual partners, or abstinence.

Since the early years of the epidemic and beyond, billions of dollars have 
been invested in prevention programs, and a significant portion of these dollars have gone to what are known as "information, education, and communications" (IEC) investments. Unfortunately, IEC by itself has not been shown to have more than a minor impact on patterns of HIV transmission and the trajectory of the epidemic (Bertrand et al. 2006). Numerous studies have shown that information alone is typically insufficient to change risk behavior. Accurate information is indisputably a basic ingredient in informed policy discourse, and information, education, and communication campaigns in conjunction with condom promotion and distribution likely results in higher condom use and significantly lower sexually transmitted infection (STI) incidence (Bertozzi et al. 2006). Behavioral change will need to be an important part of prevention strategies going forward. But the dearth of specific guidance and recommendations from the literature about what can be done to improve the effectiveness of behavioral change interventions, especially as they relate to risky sexual behavior, has been one of the more poignant failures of global response to the epidemic.

Certain other key AIDS-prevention strategies do not depend on the widespread adoption of safe sexual practices, but they nevertheless will depend on individual demand decisions to use available technologies. These include HIV and STI testing and treatment, male circumcision, and pharmacological prevention including drugs to stop mother-to-child transmission, vaginal microbicides, prophylactic antivirals, and potentially a future vaccine (Padian et al. 2011). Such clinical and technologically based approaches hold a great deal of promise; however, behavioral strategies must also be pursued. Current levels of investment in the development of new drugs, vaccines, and technologies have been at least partially fueled by the perception that behaviorally focused approaches cannot be made to work, or are politically and socially unviable. However, biomedical advances such as a cure for AIDS or the development of an effective AIDS vaccine are, at best, many years away or unattainable. Moreover, even once a clinic-based intervention, drug, or vaccine has been proven efficacious, changes in behavior are still needed to ensure access, uptake, and acceptability. Consequently, greater attention is now being given to a focus on behavioral change as an important component of prevention strategies and activities.

In the Tanzanian context in which the RESPECT trial was fielded, table 3.1 shows that knowledge of AIDS and HIV prevention strategies is extremely high and accurate, with over 99 percent of respondents familiar with HIV and 85 percent identifying condom usage as a strategy to prevent HIV. Table 3.2 further shows that a large portion of young adults have been HIV tested (a national testing campaign occurred two years earlier and testing is standard during prenatal care), and people believe that HIV rates are quite high. The average respondent estimated an HIV-prevalence rate of 17 percent among people their age in their village, indicating a high level of perceived risk. Yet table 3.2 also shows 20 percent of men admitting to 


\begin{tabular}{lcc}
\hline & $\begin{array}{c}\text { Males } \\
(N=1,175) \\
(\%)\end{array}$ & $\begin{array}{c}\text { Females } \\
(N=1,191) \\
(\%)\end{array}$ \\
\hline Heard of AIDS or HIV? & 99.8 & 99.9 \\
Can die from AIDS & 94.3 & 92.5 \\
Knowledge of prevention methods (ABC) & & \\
AIDS can be prevented by: & 97.0 & 97.4 \\
$\quad$ Just one partner & 85.6 & 84.2 \\
$\quad$ Regular condom use & 91.3 & 90.9 \\
Abstaining & 1.9 & 4.1 \\
$\quad$ Witchcraft & 97.2 & 95.6 \\
Other facts about HIV & 50.2 & 42.7 \\
$\quad$ Healthy-looking person can be HIV infected & 81.6 & 88.9 \\
$\quad$ Not being infected after having sex with HIV positive & & \\
Child can be infected during pregnancy & & \\
\hline
\end{tabular}

Source: The RESPECT project baseline survey, conducted in 2009 after project recruitment and informed consent, but prior to receiving project counseling.

The RESPECT baseline HIV test history, status beliefs, and risky behaviors

\begin{tabular}{lcc}
\hline & Males & Females \\
& $(N=1,175)$ & $(N=1,191)$ \\
& $(\%)$ & $(\%)$ \\
\hline Ever tested for HIV? & 34.8 & 71.9 \\
If yes, when last test? & Males $(N=409)$ & Females $(N=856)$ \\
$<12$ months ago & 45.7 & 45.0 \\
$12-23$ months ago & 27.4 & 28.6 \\
$>=2$ years ago & 26.9 & 26.4 \\
Received the HIV test results? & 90.9 & 92.3 \\
Perceived HIV prevalence for same age group in community & 16.0 & 18.4 \\
& $(N=1,166)$ & $(N=1,175)$ \\
On scale 0-10 what is your risk of being HIV positive? & 2.12 & 2.2 \\
& $(N=1,175)$ & $(N=1,191)$ \\
Number of partners in last 4 months & & 10.4 \\
0 & 12.2 & 86.2 \\
1 & 68.1 & 2.7 \\
2 & 15.6 & 0.7 \\
More than 2 & 4.2 & 13.8 \\
Condom use during last sexual intercourse & & 49.5 \\
With spouse or union & 15.1 & 61.3 \\
With other partner & & \\
\hline
\end{tabular}

Source: The RESPECT project baseline survey, conducted in 2009 after project recruitment and informed consent, but prior to receiving project counseling. 
multiple partners in the past month (we suspect such statistics are underreported), and close to half of participants failed to use a condom during their last sexual intercourse with a nonmarital partner. These young people appear to understand their HIV risks and know how to behave to prevent transmission-yet they do not choose to act on that knowledge. Next, we review prior experience with incentivizing individuals so as to stimulate demand for prevention.

\subsection{Literature Review on Incentives for Health Input Behaviors and Health Outcomes}

\subsubsection{Conditional Cash Transfer Approaches}

The CCT programs that provide cash to poor households in exchange for their active participation in educational and health care services have proven remarkably popular among developing country governments, sweeping the globe from Mexico to several other Latin American countries, including Columbia, Honduras, Jamaica, and Nicaragua, and much more recently, to Africa (Kakwani, Soares, and Son 2005; Nigenda and GonzalezRobledo 2005; Schuring 2005). The principle of conditionality — which may be applied differently in practice, but generally requires families to send their children to school or to receive a range of health care services, such as nutritional counseling, childhood vaccination programs, and so forthdistinguishes CCT programs from the more traditional social assistance programs that provide cash or vouchers directly to poor or otherwise distressed families with no strings attached. The CCT programs emphasize the use of market-oriented "demand-side" interventions as an instrument for longer-term human capital investments (Rawlings and Rubio 2005; Fiszbein and Schady 2009). In other words, the cash was intended to function as an incentive on credit-constrained (poor) families to invest in their children's future, recognizing the powerful limitations that short-term financial constraints placed on poor families. Ideally, they are designed to complement, rather than replace, the more familiar "supply-side" investments, which channel resources directly toward schools, clinics, and service providers.

The CCT programs that have received the most attention are those having an explicit orientation toward poverty alleviation, involving both educational and health components as part of a broader, long-term strategy of human capital investments. Such programs have been thoroughly evaluated, and overall the results of these programs have been extremely promising. The evaluations of such programs, some more rigorously designed than others, have generally shown positive impacts on health and education. Mexico's program has been evaluated most thoroughly. Studies have found increases of 25-60 percent in health care visits among children under three years of age, higher rates of nutritional monitoring, and higher immunization rates. 
In addition, caloric intake increased by 7 percent, driven by higher expenditures on fruits, vegetables, and meats. Actual health impacts have also been observed, with 12 percent lower incidence of illness among children from birth to five years old, and a height increase of one centimeter among children ages six to thirty-six months (with the greatest effects in the poorest households with educated fathers; Lagarde, Haines, and Palmer [2007]). However, very little can be surmised about the relationship between the magnitude of the transfer and the behavioral effect it induces due to the lack of experimentation with this issue. Fernald, Gertler, and Hou (2008) and Fernald, Gertler, and Neufeld (2008) have instead used quasi-experimental variation in the magnitude of Mexico's Oportunidades cash transfer to indicate that more cash is associated with better child anthropometric and cognitive outcomes (though worse adult blood pressure and obesity).

Beyond the lack of information related to cash dose response, there is also an intense debate regarding the importance of the conditionality component of such programs. Some have argued that the conditionality component is inappropriate for the African context (Schubert and Slater 2006). Even in the Latin American context, it has been recognized that it is difficult to attribute health impact to the conditionality, per se, as the programmatic intervention has many component parts, and is not limited to the conditionality (Gertler 2004; Lagarde, Haines, and Palmer 2007). In the absence of more definitive research, related programs in several countries have been launched without conditionality, including some in Africa. Several more recent studies are now analyzing conditionality compared to randomized arms with unconditional cash payments, yielding sometimes surprising results. For example, Baird, McIntosh, and Ozler (2011) find that conditionality improves adolescent girl school outcomes in a CCT program in Malawi, but increased teen pregnancy and marriage rates relative to unconditional transfers. More will be known to help interpret these complex relationships as additional studies such as this are released in the near future.

Overall, the evidence from an impressive collection of evaluations of CCTs as part of a broader poverty alleviation strategy demonstrates that such programs are feasible and effective. Such programs have demonstrated positive impacts on uptake rates of health (and education) services, and, in some cases, marked improvements in health outcomes (Sridhar and Duffield [2006] review nutritional outcomes, in particular). However, it is important to note that the evidence on how and whether the conditionality works remains weak. For STI/HIV prevention, this is the most critical piece of information that is needed to assess whether similar types of programs can be effective at reducing risky sexual behavior. To explore the role of conditionality in more detail we next turn to contingency management approaches, which typically use much smaller payments that would be unlikely to have income effects on behavior, and thus better isolate the role of the conditionality incentive per se. 


\subsubsection{Contingency Management Approaches}

Similar to CCTs, contingency management (CM) relies on the mechanism of conditionality to elicit behaviors that are viewed to be in one's longterm interests (or, those of society's), and to discourage those behaviors that may be ultimately detrimental to one's own health and well-being that may not be easily perceived or experienced in the short term. There are several key differences between CCT and CM, though. First, CCT programs typically have much larger cash rewards for complying with conditionality, hence exploit both price and income effects on behavior. Second, CCT programs have typically conditioned on easily monitored input behaviors (such as health care use), whereas $\mathrm{CM}$ has been used for behaviors that are harder to monitor directly (such as drug use), and hence CM conditions instead on the desired outcome (negative drug test). Third, while the CCT incentivized inputs (a prenatal care visit) require a "simple" behavioral response over which the individual has a high degree of control, CM incentives often require a "complex" behavioral change (over which the individual may have imperfect control; Kane et al. [2004]). This complexity may require changing multiple behaviors, reversing habit formation and addictive behaviors, and judging uncertainty (such as probability that a behavior will indeed cause a negative test).

The CM applications span many areas of risky behaviors, including substance abuse, smoking, and overeating. It has been especially well studied by clinical psychologists as a therapeutic approach to encourage the practice of healthful behaviors and to discourage unhealthy behavioral practices, especially those that may be linked to addiction or other destructive behaviors that are deeply engrained and/or habit forming. The CM interventions provide "reinforcers" (e.g., incentives or rewards) contingent on an individual's abstinence from a target drug or behavior. The reinforcement device, often cash payments, vouchers, or prizes, is contingent upon an objective measure of a predetermined therapeutic target. An "objective" measure often means a biochemical measure such as urine toxicology testing or the measurement of breath alcohol or carbon monoxide levels instead of self-reported compliance, which is not verifiable.

The essential principles of CM, as outlined by Petry (2000), are to reinforce the treatment goals by (a) closely monitoring the target behavior; (b) providing tangible, positive reinforcement of the target behavior; and (c) removing the positive reinforcement when the target behavior does not occur. The CM techniques have been developed and tested in the context of clinical trials and settings, and are a clinically accepted tool in fields such as substance abuse, but have rarely (if ever) been implemented on a large scale in the manner of CCT programs.

As with CCTs, CM interventions have been tied to participation and the 
uptake of services in several domains, although risk behaviors are the important determinant for participant selection, rather than income constraints. The CM has been shown to improve drug abuse outcomes (Rawson et al. 2002) and uptake rates of counseling sessions (Petry et al. 2001); attendance at weight loss sessions; attendance at HIV drop-in center activities (Petry, Martin, and Finocche 2001) and antiviral medication adherence (Rosen et al. 2007); and attendance in smoking cessation clinics (e.g., see Higgins et al. 1994; Petry 2000; Emont and Cummings 1992). Of particular interest, however, is the use of CM to elicit a complex behavioral change-usually, to discourage an unhealthy behavior by positively reinforcing the cessation of that activity (e.g., drug or alcohol abuse, smoking, or overeating). The conceptual basis of CM and CCTs is thus largely similar, although advocates of CM impose no a priori assumptions about the effectiveness of the use of cash as the incentive or reinforcement device, and have experimented with a variety of reward mechanisms, including vouchers and prizes. ${ }^{2}$ In addition, many $\mathrm{CM}$ studies are designed to explore effect differences due to variations in the value of the conditionality (known as the "dose-response" curve), the frequency of monitoring and payments, and the length of time that the elicited behavior change is sustained after the program has ended.

The use of CM has been most intensively studied in relation to its efficacy in treating substance abuse. A landmark study by Higgins et al. (1994) demonstrated that incentives delivered contingent on submitting cocainefree urine specimens significantly improved treatment outcomes in ambulatory cocaine-dependent patients. Over 50 percent in the treatment condition achieved at least two months of cocaine abstinence versus only 15 percent of the controls. Silverman et al. (1996) showed that 47 percent of cocaineabusing methadone patients assigned to the CM group achieved more than seven weeks of continuous abstinence, compared to only 6 percent of patients in the control group who achieved more than two weeks of abstinence. Similar results have been found for treating opioid dependency (Petry 2000). While CM has also been shown efficacious in treating alcohol abuse, the studies are fewer in number due to the difficulties associated with objectively verifying abstinence. Breath, urine, and blood tests can detect alcohol use only up to four to eight hours, which means that effective monitoring would have to take place two or three times a day (Stitzer and Petry 2006).

Financial incentives to discourage smoking have also been extensively studied. Donatelle et al. (2000) used social support and financial incentives to induce high-risk pregnant smokers to quit during their pregnancies. They provided in the amount of $\$ 50$ per month for each month of absti-

2. The findings of studies reviewed for this chapter suggested that cash is typically preferred by research subjects, and in some studies it has been shown to have a greater behavioral effect than the equivalent noncash reward (Kamb et al. 1998; Deren et al. 1994; Vandrey, Bigelow, and Stitzer 2007), although the findings are hardly conclusive. 
nence (up to a maximum ten-month period, which included two months of postpartum). Lab-verified abstinence was required, and the biochemically confirmed quit rates within the treatment group were higher both at eight months and two months postpartum. Stitzer and Bigelow (1983) experimented with different levels of cash payment, providing a payment of $\$ 1, \$ 5$, or $\$ 10$ per day for ten days to the three treatment groups (the control group received no cash). The study found that $\mathrm{CO}$ levels decreased in an orderly fashion as pay increased. However, another study by Windsor, Lowe, and Bartlett (1988), which provided cash payments of \$25 at six weeks and six months as a reward for abstinence, found no difference in cessation rates between the control and treatment groups. Other earlier studies experimenting with prizes, vouchers, and in-kind gifts of free nicotine patches showed mixed results, but even positive results disappeared after six months. More recently, Volpp et al. (2009) found that while an incentive program's effects on smoking cessation also declined after withdrawal of the incentives, significant effects did still remain three to six months later.

The use of financial incentives to treat obesity has also gained in popularity, but the evidence regarding efficacy is decidedly more mixed (see e.g., Follick, Folwer, and Brown 1984; Jeffery, Thompson, and Wing 1978; and Jeffery et al. 1984.) For example, Volpp et al. (2008) found significant weight loss from a lottery-based incentive program, but they were not sustained four months after the program's end; similarly, John et al. (2011) found matched commitment contracts led to significant weight loss after thirty-six weeks, but again it was not sustained during a thirty-two-week postincentive period. A recent systematic review of randomized controlled trials of treatments for obesity (Paul-Ebhohimhen and Avenell 2008) showed no significant effect of the use of financial incentives on weight loss or maintenance at twelve months and eighteen months. However, further subanalysis indicated that large transfers (greater than 1.2 percent of personal disposable income) had greater impact, as did rewards for behavioral change rather than weight loss, per se, and rewards based on group performance rather than individual results.

The CM literature, overall, offers useful insights into aspects of the conditionality that appear to elicit the desired behavior change. This is an important area of inquiry that has not been sufficiently explored within CCT programs. However, unlike CCT programs, studies of CM have remained largely experimental and have not been brought to scale (Petry 2000; Kane et al. 2004). Furthermore, the small sample sizes of study groups-most typically involving groups of 20 to 100 , and rarely more than 500 - have made it difficult to detect effects that are statistically significant, much less estimate effect sizes accurately. Also, factorial designs with several treatment arms are common which - in combination with already small sample sizes - has led to even more constraints on power (Kane et al. 2004). 


\subsection{Theoretical Pathways for Incentive Effects on Risky Sexual Behaviors}

As indicated in the above literature review, there are a variety of theoretical pathways via which incentives could influence risky sexual behaviors. In the STI domain, such behaviors might include sexual behavior (abstinence, fewer partners, less risky partners, condom use, pressure spouse/partner to reduce risky behaviors) as well as testing and treatment behaviors (regular STI testing, STI treatment, and encouraging partner to do the same). In this section we focus on behavioral changes induced particularly by incentives such as those employed in the RESPECT study: cash rewards conditional on testing negative for STIs.

\subsubsection{Neoclassical Price Effect}

Neoclassical economics predicts that the incentives will influence behavior in part via a price effect. Conditioning the reward on STI status increases the implicit "price" of risky sex, since there is now a potential loss of cash associated with risky behaviors. This theory assumes rational decision making in the sexual domain (Philipson and Posner 1995). The idea that individuals make trade-offs between price and the riskiness of sex is consistent with Gertler, Shah, and Bertozzi (2005), who find Mexican sex workers charge higher prices for sex without condoms, and Robinson and Yeh (2011) who find that sex workers charge more for anal sex. This, of course, does not indicate that individuals are perfectly rational in such decisions, but lends credence to the idea that people do respond to sex prices. However, this price effect may be muted by the fact that not all risky behaviors will result in a positive STI test, so the expected loss may be lower than the reward value. In the RESPECT trial, approximately 10 percent of individuals tested positive at each time point, thus a person of average risk who mixes with average risk partners could have an expected loss of only one-tenth of the reward amount. For example, the RESPECT study's higher cash reward amount of \$20 might yield only a \$2 "price" of risky sex during a fourmonth period, which by itself could be a weak spur to behavioral change.

\subsubsection{Neoclassical Income Effects}

To the extent that health is a normal good, the rewards may change behavior through income effects, particularly with increasing value of cumulative repeated rewards. In many $\mathrm{CM}$ applications, though, the reward amounts are sufficiently small as to preclude neoclassical income effects. In the RESPECT study, the rewards over one year can be as high as 25 percent of mean annual earnings, which is a substantial amount. For some lowerincome women this could indeed ameliorate immediate economic pressures to engage in transactional sex, although there is mixed evidence on the size and even sign of the income effect on risky sexual behaviors. For men in 
particular, it is often hypothesized that higher income will lead to more transactional sex, which over time would mute the incentive effects on male sexual behaviors.

\subsubsection{Systematic Cognitive Errors}

Some individuals may not be able to accurately perform the expected value calculations discussed above. Limited numeracy, availability heuristics, and bounded rationality may make some people particularly prone to systematic overestimation of small STI probabilities (see e.g., Kahneman and Tversky 1979). Thus they may behave as if the expected loss is substantially higher than it truly is.

\subsubsection{High Discounting}

In a society with a generalized AIDS epidemic (Tanzania has an estimated 6 percent adult prevalence rate), the expected cost of an AIDS diagnosis might be considered far larger than the modest cash rewards offered. For individuals who are present focused and heavily discount the future though, the prospect of an AIDS diagnosis many years in the future may not be considered a high cost. But if the price of risky sex would be incurred within months instead (the RESPECT study tested and offered cash rewards every four months), then high discounters may perceive an increased (discounted) price of risky sex, and thus behaviorally respond to this shortening of the time horizon. This, of course, depends on the extent of high discounting; studies in this context (including measures in the RESPECT study) have found extremely high rates of discounting, implying that even a time frame of months may result in substantial discounting of the potential reward value. And a reward in the time frame of months may have little impact on those risky sexual behaviors that may be driven by strong hyperbolic discounting (similar to the concept of compulsive immediate gratification used in developmental psychology) as discussed in the behavioral economics literature (O’Donoghue and Rabin 2001).

\subsubsection{Other "Nudges"}

A variety of other behavioral economics and psychological hypotheses have been proposed regarding the operation of incentives, now sometimes referred to as "nudges" following the popularization of the term by Thaler and Sunstein (2008). For example, some argue that introducing explicit monetary incentives into the sexual decision-making process may alter the frame within which people assess costs and benefits, resulting in unpredictable deviations from neoclassical theory. Others suggest that the incentives provide individuals with an excuse for deviating from social norms in order to act on underlying preferences for less risky behavior. Several such theories would predict a discontinuity of the dose-response relationship at zero: the first positive reward amount should have much larger behavioral 
effects than subsequent amounts. Designing studies with multiple reward amounts (RESPECT used $\$ 20, \$ 10, \$ 0$ ) will be particularly important for testing such hypotheses.

In addition to the above discussed pathways for behavioral change in response to the incentives, it is also useful to consider potential long-term effects of time-limited incentives. Two competing hypotheses are of particular interest:

\section{Learning}

For behaviors that individuals may not have tried until encouraged to by the incentives (e.g., use of condoms), it is possible that the incentives will induce learning (and reinforcement) that could result in permanent positive behavior changes even after withdrawal of the incentives.

\section{Reduced Intrinsic Motivation}

Alternatively, psychologists have emphasized the potentially pernicious effects of extrinsic monetary incentives in destroying the intrinsic desire to engage in positive behaviors. Cameron, Banko, and Pierce (2001) reviews the literature on the possible destruction of intrinsic incentives and concludes that while this might occur for some high-interest tasks, in general, incentives do not have pervasive adverse effects.

\subsection{The RESPECT Study: Design Considerations and Lessons Learned}

In this section we highlight major considerations in designing a sexual behavior incentive study, providing rationale for choices made in designing RESPECT, so as assist others in designing similar studies in the future. Table 3.3 provides 2009 baseline summary statistics on key variables discussed below. Further details of the RESPECT study are described elsewhere (de Walque et al. 2012).

\subsubsection{Ethical Considerations}

Ethical concerns permeated all aspects of project planning, as referred to in many of the subsequent sections. The use of incentives in the sexual arena raises many potential controversial issues, so it is also natural that there will be disagreement regarding ethical considerations, both across individuals and across cultural settings, thus it is essential to have careful oversight and scrutiny of the research design and protocols. The project underwent several rounds of ethical review by several different committees and agencies, including the IRBs of the University of California, Berkeley and San Francisco, the Ifakara Health Institute, and the National Institute for Medical Research in Tanzania (NIMR). In addition, the study benefited from a (largely Tanzanian) ethical advisory group that reviewed the study protocol. 
Table 3.3

The RESPECT baseline summary statistics, among full-year panel sample and those attriting by one-year endpoint

\begin{tabular}{lccc}
\hline Variables & Mean among followed & Mean among attrited & Proportion attrited \\
\hline Arm & & & \\
$\quad$ Control & 0.46 & 0.54 & $0.076^{*}$ \\
$\quad$ Low value & 0.28 & 0.19 & 0.064 \\
$\quad$ High value & 0.26 & 0.27 & $0.049^{*}$ \\
Female & 0.51 & 0.43 & $0.056^{*}$ \\
Age & 27.49 & 25.85 & - N $^{* *}$ \\
Education & & & \\
$\quad$ None & 0.12 & 0.11 & 0.063 \\
Primary & 0.78 & 0.75 & 0.063 \\
Secondary & 0.10 & 0.13 & 0.084 \\
Married & 0.76 & 0.61 & $0.053^{* * *}$ \\
Low SES & 0.55 & 0.51 & 0.061 \\
Income & 258.25 & 223.06 & 0.058 \\
Chlamydia & 0.02 & 0.02 & 0.136 \\
Gonorrhea & 0.01 & 0.02 & 0.077 \\
Trichomonas & 0.12 & 0.15 & 0.063 \\
HSV2 & 0.35 & 0.33 & 0.075 \\
Syphilis & 0.02 & 0.02 & $0.212^{* * *}$ \\
HIV & 0.03 & 0.12 & 0.065 \\
$N$ & 2,242 & 157 & \\
\hline
\end{tabular}

Source: The RESPECT project baseline survey, 2009.

Notes: Low SES is an indicator for response $<=3$ on a $1-7$ ladder of subjective social status in the community. Income is an individual's annual earnings in thousands of Tanzanian shillings (in 2009 the exchange rate for dollars was US\$1 $\sim=$ TSh 1,100-1,300, yielding average earnings of about $\$ 200 /$ year).

***Significant at the 1 percent level.

**Significant at the 5 percent level.

*Significant at the 10 percent level.

\subsubsection{Target Population}

A key decision point is whether to target the general population of some region, or target a particular high-risk group. The intervention may be on average more effective among high-risk groups, but potentially have a smaller aggregate impact. The RESPECT study chose to target a general population. A pilot study by Galarraga (in process) in Mexico City is alternatively exploring the possibility for targeting a group of male sex workers. One concern with targeting a group such as sex workers is the political constraint to scaling-up implementation due to stigma and/or the concern about the rewards attracting people to sex work; however, the income value of sex work is likely to swamp the value of incentive payments, making that concern less salient.

In order to ease study logistics, RESPECT chose to implement the inter- 
vention within the context of Ifakara Health and Demographic Surveillance Site in rural southwestern Tanzania. We chose to recruit from ten villages; eight were rural and two were in Ifakara town. Rural villages are generally lower income, so a given reward level is likely to be more salient. Due to the limited number of villages, study-arm randomization occurred at the individual level.

Demographically, we chose to enroll both men and women, as both could hypothetically respond to the program. A priori, there were concerns that women might not have sufficient agency to respond to the incentive regimen, while there were concerns that men's responses could be dulled if they used cash rewards to pay for new risky behaviors, thus it was of interest to study both genders. We also chose to enroll both single and married individuals, and married individuals were issued invitations for their spouse to join the study as well (in the same intervention arm).

Regarding age group, we initially sought to enroll fifteen to twenty-fouryear-olds (a particularly high-risk age group), but due to ethical concerns we decided not to enroll minors, thus our final target range was eighteen to thirty-year-olds (plus all spouses ages sixteen or older).

For recruitment we chose a random sample of village residents from the demographic surveillance site computer registry, and went to each of their houses to explain the study and invite them to participate by reporting to a study station set up in their village the following week. Of individuals who were reached in their houses for recruitment, approximately 70 percent came to the study station and enrolled. Thus the enrolled sample is highly representative of the general population of eighteen to thirty-year-olds in these villages. Table 3.3 further shows that only 6.5 percent of enrollees attrited or were lost to follow-up during the one-year intervention. Attriters were younger and more likely to be single, but overall means of those choosing to complete the study were quite similar to attriters, except for the fact that attriters were substantially more likely to be HIV positive at baseline (with 21 percent of HIV positives attriting, possibly due to confusion about continued study eligibility). With this exception, the study sample was highly representative of the underlying population.

\subsubsection{Conditionality Design}

A primary goal of the study was to reduce risky sexual behaviors. But because these were not directly verifiable, we instead opted to link cash payments to objective measures - STI test results - that could serve as (imperfect) proxies for risky sexual behavior. Ideally we wished to condition on only STIs, which have been incontrovertibly linked to solely risky sexual activity. We also needed to balance cost considerations with the imperative to have enough tests so as to sufficiently capture risky behavior. In addition, we needed to consider local knowledge of STIs, testing capacity, and availability of appropriate drugs with low rates of treatment failure. Because RESPECT 
was designed as a "proof of concept" to detect whether or not individuals appeared to responded to this type of incentives related to sexual behavior, we chose to conduct an expansive set of tests. These were: chlamydia, gonorrhea, trichomonas, Mycoplasma genitalium, syphilis, and HSV2. Each had unique considerations: chlamydia and gonorrhea were well known among the target population, thus, although they ended up having relatively low prevalence overall, they were useful to include due to their salience in the target population. Trichomonas has the merit of fairly high prevalence (and presumed incidence), although additional complications are introduced by the fact that it is biologically more common among women than men. Mycoplasma genitalium is also a high-prevalence STI, but has the drawback that it is not well known (many clinicians in this setting are unaware of it), there are no rapid tests for it, and treatment failure rates are not well understood; for these reasons we opted not to condition rewards on this STI, but still measured it for the purposes of increasing statistical analysis power.

For highly reliable measurement of these first four STIs, every four months we collected urine samples from men and vaginal swabs from women (performed by a local nurse after careful explanation and consent - acceptability of swabs did not turn out to be problematic), and conducted assays using nucleic acid amplification tests (NAAT) at the Ifakara Health Institute microbiology lab. The NAAT tests were chosen because of their high sensitivity, but they are also expensive and thus would not normally be possible to do if scaling-up the intervention; a more feasible design for scale would be to focus just on a subset of STIs with reliable rapid tests. Use of laboratory-based NAAT testing also required a two- to three-week period in order to process all of the tests, thus we had to ask participants to return to their village study station to pick up the tests. Over 90 percent of participants came back to collect their results three weeks later, even in the control group; this is likely due to a combination of the fact that this is a population accustomed to research studies, as well as the high level of interest people had in "knowing their status" and rechecking it regularly (for both HIV and STIs). This also had the added benefit that we had another contact with study participants to remind them of the study and also provide individual posttest counseling (pretest counseling was provided to all at the time of specimen collection). Individuals who tested positive were provided vouchers for themselves and up to five partners for free treatment at the local health clinic, and a system was put into place to ensure that the first- and secondline medicines were always available in those clinics. A critical point is that each of these four urine-based STIs is curable. Thus, enrollees who test positive for an STI can continue to participate in the intervention after they have been treated and cured of the infection; learning is encouraged through positive reinforcement, and mistakes can be corrected and overcome.

In addition to these urine-based NAAT STI tests, we also measured syphilis and HSV2 using blood-based tests. Because of the low prevalence 
of syphilis, and because HSV2 detects whether the individual has ever contracted HSV2, we elected to only measure these blood-based STI's at baseline and twelve months, rather than at each four-month interval.

Finally, we also measured HIV at baseline and one-year follow-up. We did not condition reward payments on HIV status, in part due to ethical concerns about "punishing" somebody at the very time when they learn that they have contracted a fatal disease. We were not powered to look at intervention arm effects on HIV, but for scientific purposes did want to measure baseline HIV to better characterize our population. Our HIV rates turned out to be lower (just under 4 percent) than anticipated based on regional Demographic and Health Survey data; given the reasonably high rates of HIV testing in the population, it may be that HIV-positive individuals selected themselves out of the sample. We decided to also test HIV at the twelvemonth endpoint due to the study population's strong interest in checking their results again. Although over half of the population had received a prior HIV test, study enrollees expressed concerns about confidentiality of testing at local clinics, and strong desire for retesting by RESPECT study personnel.

\subsubsection{Incentive Size and Frequency}

A major design consideration is the size of the incentive. The CCT programs focused on uptake have typically relied on formulas to compensate participants on the opportunity costs, or time requirements, of complying with programmatic requirements such as attending antenatal care visits or taking the child to the clinic for his or her regular check-ups. However, in the case of CCT programs designed to encourage safer sexual practices and discourage risky ones, the purpose of the incentive is not primarily to compensate the individual for the opportunity costs of participating in the program, but rather to change the decision calculus of the individual regarding his or her sexual behavior. The goal would be to increase the immediate costs associated with risky behavior by increasing the possibility of future reward (cash). Several studies of the CM interventions have found a positive relationship between the magnitude of the reward and the impact on the target behavior (and laboratory-confirmed health impact; Sindelar, Elbel, and Petry 2007; Stitzer and Bigelow 1983), at least during the treatment period; the effect appears to weaken during follow up (Higgins et al. 2007). However, the magnitude of incentive required for shaping sexual behavior is unknown. Preliminary assessments can be obtained through focus group discussions, survey data, and discrete choice experiments, but these are no substitute for direct measures of impact achieved by randomly assigning different-sized payments to individuals participants.

In the RESPECT study, we chose an incentive amount of approximately $\$ 20$ at each four-month testing point. Mean earnings in the study population are approximately $\$ 200$ per year, thus staying STI negative could increase income by about 30 percent, which is in a similar ballpark as Mexico's 
Oportunidades program. This amount was discussed extensively with local populations, some of whom argued for much higher amounts (which would not be able to be feasibly scaled-up), but others of whom agreed that $\$ 20$ sounded reasonable. We then chose to include a second incentivized arm with a reward half that size, in order to test dose response. One concern about our ability to test this dose response, however, is that randomization is at the individual level, thus individuals in the $\$ 10$ group may feel "cheated" and respond less robustly than if they were not aware of the higher group.

In addition, we also chose to assess the acceptability and feasibility of lottery-based incentives. All enrollees were eligible for a $\$ 100$ village and gender-specific lottery drawing at the four-month, eight-month, and twelve-month testing rounds (thus, on average, the chances of winning were approximately one in one hundred at each four-month time point). However, if individuals in the cash reward arms tested STI positive, they were made ineligible for the lottery in that round (control enrollees were eligible regardless of their STI status, as long as they had not attrited from the project). Thus, this equally reinforced incentives for both of the incentivized reward arms. The lottery proved popular, as our ex ante focus groups had predicted (the national lottery is also popular). Large crowds attended each drawing, providing yet another opportunity to communicate project messaging. The lottery had two limitations to consider, though. First, some winners were individuals known in the community to engage in risky sexual behavior, which cause disillusionment among some village members. Second, the incentive structure was confusing to some enrollees, violating the "KISS" principle (keep it simple stupid); this could be remedied though in a simpler lottery-only design. At the end of the study we queried individuals about the role of the cash rewards versus the lottery; in general, people indicated that their behaviors responded to both sets of incentives in roughly equal proportions, providing promising evidence for the potential of pursuing (lower cost) lottery designs in future interventions. This needs to be counterbalanced against the finding in table 3.4 that although respondents generally "liked" both the cash rewards and the lottery, they liked the former somewhat more.

A separate but related consideration is the frequency and immediacy in which the cash incentive is paid out. Given the unplanned and spontaneous nature of many sexual encounters, the incentive needs to be offered frequently enough to keep it ever present in the minds of the target group, and as immediately as possible to reinforce the link between the payment and the target behavior. It seems reasonable to assume, and the CM literature has confirmed (Stitzer and Petry 2006), that larger cash payments given frequently have greater impact than smaller payments given less frequently, but it is nevertheless unclear how these two dimensions of magnitude and frequency interact. In the RESPECT study we chose to balance the frequency with budgetary imperatives by testing every four months, although given 


\begin{tabular}{|c|c|c|c|c|c|c|c|}
\hline \multirow[b]{2}{*}{ Arm } & \multirow[b]{2}{*}{ Award type } & \multirow[b]{2}{*}{ Value } & \multirow[b]{2}{*}{$N$} & \multicolumn{4}{|c|}{$\begin{array}{l}\text { How much does/would motivate } \\
\text { behavior change? (percentage) }\end{array}$} \\
\hline & & & & Very much & Somewhat & A little & None \\
\hline \multicolumn{8}{|c|}{ Rewards: Eight-month survey } \\
\hline Low value & Actual & 10,000 & 486 & 36 & 21 & 12 & 31 \\
\hline High value & Actual & 20,000 & 518 & 59 & 13 & 7 & 21 \\
\hline Control & Hypothetical & 10,000 & 172 & 24 & 21 & 12 & 43 \\
\hline Control & Hypothetical & 20,000 & 264 & 47 & 11 & 10 & 32 \\
\hline Control & Hypothetical & 50,000 & 232 & 57 & 13 & 8 & 23 \\
\hline Control & Hypothetical & 100,000 & 195 & 57 & 7 & 5 & 31 \\
\hline \multicolumn{8}{|c|}{ Rewards: Twelve-month survey } \\
\hline Low value & Actual & 10,000 & 150 & 57 & 27 & 7 & 9 \\
\hline High value & Actual & 20,000 & 160 & 79 & 13 & 4 & 5 \\
\hline Control & Hypothetical & 10,000 & 254 & 51 & 20 & 9 & 19 \\
\hline Control & Hypothetical & 20,000 & 239 & 65 & 19 & 4 & 12 \\
\hline Control & Hypothetical & 50,000 & 279 & 70 & 19 & 3 & 9 \\
\hline Control & Hypothetical & 100,000 & 258 & 77 & 14 & 2 & 8 \\
\hline \multicolumn{8}{|c|}{ Lottery: Twelve-month survey } \\
\hline Low value & Actual & 100,000 & 209 & 87 & 6 & 2 & 5 \\
\hline High value & Actual & 100,000 & 175 & 89 & 4 & 0 & 7 \\
\hline Control & Hypothetical & 50,000 & 345 & 78 & 13 & 2 & 7 \\
\hline Control & Hypothetical & 100,000 & 349 & 83 & 7 & 2 & 7 \\
\hline Control & Hypothetical & 200,000 & 336 & 80 & 10 & 1 & 9 \\
\hline
\end{tabular}

Notes: Control-arm respondents were randomly assigned a single hypothetical reward value and a single lottery value, about which the behavior change motivation question was asked. Respondents in the lowvalue and high-value arms were asked about their actual reward amounts. Low-value and high-value sample sizes are reduced at twelve months because a portion of these respondents were instead randomized to questions about other hypothetical arms (not shown).

the lack of guidance in the literature this was inevitably a somewhat arbitrary decision. Of additional interest is whether the cash incentive should be paid directly to individuals, to a couple, or some other social grouping. The CCT programs for poverty alleviation have tended to target households and communities, but the incentive is actually paid to the mothers of young children, rather than the fathers or the legal head of household. This design feature has been a nod to a series of findings that women are more likely to use the money on food for the family rather than on alcohol or other purchases (Rawlings and Rubio 2005; Schady and Rosero 2007). However, some studies of CM interventions have found that the effect size of incentive was greatest if the payment was made to a predesignated group rather than the individual (Jeffery et al. 1983). This may be due to the social support provided by the group, peer pressure, or some combination, and the question is whether such a mechanism can or should be applied to the sexual relationship. In the RESPECT study, we chose the clearest and most 
transparent method: paying each individual separately. Data analysis indicates that many of the individuals shared their rewards by buying household goods, but many others (both men and women) kept the funds to themselves and did not even share with their spouse.

\subsubsection{Skill Building to Aid Behavioral Change}

In order to ensure that participants had the necessary tools to act on the incentives for sexual behavior change, we chose to offer monthly (sex segregated) group skill-building sessions (in addition to individual preand posttest counseling every four months). For this purpose we trained local facilitators to deliver a modified version of the Stepping Stones curriculum (Jewkes et al. 2008), with sessions on topics such as sexual health, condom use, relationship skills, decision-making skills, women's roles and gender-based violence. The last of these was particularly important due to the concern that women testing STI positive may be subject to violence; for this purpose we also carefully monitored for violence events. Fortunately, reported violence rates during the intervention were consistently lower than preintervention levels (Krishnan et al. 2012). We chose to make these group sessions voluntarily, and 20-30 percent of enrollees attended each month.

\subsubsection{Self-Reported Degree of Behavioral Change Motivation from Incentives}

To judge the overall perceived effectiveness of the incentive mechanisms used in RESPECT, table 3.4 presents enrollees' responses to direct questions regarding how much the incentives motivated sexual behavior change. At both eight-month and twelve-month time points the low-value and highvalue respondents were asked how much the cash rewards motivated sexual behavior change. After eight months, 36 percent of low-value arm (TSh $10,000)$ respondents stated "very much" and 31 percent stated "none." In the high-value arm (TSh 20,000), the percent stating "very much" was substantially higher at 59 percent, with only 21 percent reporting "none." The control-arm respondents were also queried, but as part of this question each was randomized to a single hypothetical reward amount (TSh 10,000/ $20,000 / 50,000 / 100,000)$ and asked how much that amount would motivate behavior change. Table 3.4 reports again a consistent dose-response relationship, with higher amounts related to higher self-reported behavioral change motivation. Interestingly, those actually enrolled in the reward arms reported higher levels of motivation than did the control respondents when reporting about the hypothetical reward scenario.

These motivation questions were repeated again at the twelve-month intervention end point, as reported in the middle panel of table 3.4 (the questions were not asked prior to the eight-month survey). The above doseresponse patterns were replicated. A further finding is that reported motivation levels are uniformly higher at twelve months than they were at eight 
months, suggesting that there may have been further learning and behavior change by participants during this interval, which is an argument for repeated rounds of incentivized behavior over an extended period of time. By this end point, 79 percent of the high-value arm enrollees reported "very much" motivation, with only 5 percent reporting no motivation.

Finally, the bottom panel of table 3.4 reports on parallel questions that were asked at twelve months in regard to the lottery incentives. We first note that 89 percent of high-value arm respondents reported "very much" motivation from the lottery, which is even higher than for the cash rewards. This is despite the fact that the respondents had already participated in two rounds of the lottery, after which they should have been aware that the odds of winning the actual 100,000 lottery were approximately 1 percent, thus the expected value of the lottery was far lower than the certain cash rewards. Second, we note that the responses by control individuals (asked to imagine a single hypothetical lottery amount in which eligibility was conditioned on negative STI results) were quite similar to those of the actual high-value and low-value arm respondents; perhaps the fact that the control-arm enrollees had already been actually eligible for the lotteries (but regardless of STI status) had made them better informed about how the lottery could affect their motivation. Third, it is evident from table 3.4 that there is not a dose-response relationship between the different hypothetical lottery amounts and the degree of projected behavior change motivation. This is despite the fact that these control respondents had all been "anchored" by the actual lottery amount of TSh 100,000, and thus might be particularly expected to react negatively to the lower hypothetical amount of 50,000. One potential explanation for this lack of a dose-response relationship is that the lottery amounts tested were all sufficiently high (TSh100,000 is equal to approximately 40 percent of mean annual income in the study population) that virtually all respondents would be motivated by the prospect of winning. Indeed, in-depth focus group responses suggested that many individuals in this context failed to calculate the relevant expected value (few have completed schooling beyond the primary level), and thus were likely making cognitive errors that led to greater salience of the lottery than would be rationally expected. Although we must be cautious in not overinterpreting these self-reported "motivation" questions, and should await publication of further results from the more objective STI endpoints, this evidence does suggest that a lottery-based incentive system may be acceptable within this community and possibly be more cost effective than a system of certain rewards.

\subsection{Discussion}

Cash incentives have been shown to be effective at shaping behavior in a variety of health domains, from improving the uptake of health and edu- 
cational services among the poor, to discouraging unhealthy or risky behaviors, such as substance abuse, smoking, and overeating. These successes inevitably raise the question of whether they can also be applied in areas of sexual and reproductive health beyond contraception (Mauldon 2003; Weeden et al. 1986), and in particular to HIV prevention (Haug and Sorenson 2006). A review of countries' experiences with CCT programs for poverty alleviation and $\mathrm{CM}$ provides useful insights into how to design, implement, and evaluate a CCT-based STI/HIV prevention intervention. The particular experience of the RESPECT study finds that such a program can be designed to be efficacious and acceptable.

Tables 3.5A and 3.5B report enrollee responses to questions regarding perceived success of the trial and which dimensions of the trial they liked and did not like. Although such responses must be interpreted cautiously in light of possible social desirability bias (not wanting to offend the interviewer) - indeed there is some variation in responses across questions-

Table 3.5A

Enrollees' attitudes toward elements of RESPECT, after one-year trial

\begin{tabular}{|c|c|c|c|c|}
\hline & & High value & Low value & Control \\
\hline \multicolumn{5}{|c|}{ What aspects of RESPECT did you like: } \\
\hline \multirow[t]{4}{*}{ HIV testing } & Very much & 96.2 & 95.3 & 92.4 \\
\hline & Somewhat & 2.7 & 3.6 & 5.1 \\
\hline & A little & 1.0 & 1.0 & 2.4 \\
\hline & None & 0.0 & 0.0 & 0.0 \\
\hline \multirow{4}{*}{ STI testing } & Very much & 98.5 & 97.2 & 96.8 \\
\hline & Somewhat & 1.4 & 2.1 & 3.0 \\
\hline & A little & 0.2 & 0.3 & 0.2 \\
\hline & None & 0.0 & 0.3 & 0.0 \\
\hline \multirow[t]{4}{*}{ Cash rewards } & Very much & 93.2 & 87.7 & 60.1 \\
\hline & Somewhat & 5.6 & 8.9 & 24.8 \\
\hline & A little & 1.2 & 2.8 & 13.0 \\
\hline & None & 0.0 & 0.7 & 2.0 \\
\hline \multirow[t]{4}{*}{ Lottery } & Very much & 74.5 & 69.9 & 54.4 \\
\hline & Somewhat & 18.6 & 20.6 & 27.4 \\
\hline & A little & 5.8 & 8.1 & 14.8 \\
\hline & None & 1.0 & 1.5 & 3.5 \\
\hline \multirow[t]{4}{*}{ Free STI treatment } & Very much & 96.4 & 96.8 & 95.0 \\
\hline & Somewhat & 3.1 & 2.1 & 3.6 \\
\hline & A little & 0.5 & 0.8 & 1.2 \\
\hline & None & 0.0 & 0.3 & 0.2 \\
\hline \multirow[t]{4}{*}{ Individual counseling } & Very much & 88.0 & 83.6 & 82.4 \\
\hline & Somewhat & 9.1 & 12.8 & 13.7 \\
\hline & A little & 2.6 & 3.1 & 3.8 \\
\hline & None & 0.3 & 0.5 & 0.1 \\
\hline \multirow[t]{4}{*}{ Group counseling } & Very much & 58.6 & 54.3 & 50.0 \\
\hline & Somewhat & 21.0 & 21.1 & 20.4 \\
\hline & A little & 17.1 & 20.9 & 23.1 \\
\hline & None & 3.3 & 3.7 & 6.7 \\
\hline
\end{tabular}




\begin{tabular}{|c|c|c|c|c|}
\hline & & $\begin{array}{l}\text { High } \\
\text { value }\end{array}$ & $\begin{array}{c}\text { Low } \\
\text { value }\end{array}$ & Control \\
\hline \multicolumn{5}{|c|}{ At end of one-year study did RESPECT: } \\
\hline \multirow[t]{4}{*}{ Reduce STIs in village } & Very much & 91.6 & 90.3 & 86.2 \\
\hline & Somewhat & 7.2 & 7.3 & 10.9 \\
\hline & A little & 0.7 & 1.6 & 2.0 \\
\hline & None & 0.5 & 0.8 & 0.9 \\
\hline \multicolumn{5}{|c|}{ How did RESPECT study affect: } \\
\hline \multirow[t]{3}{*}{ Your life } & Greatly improved & 74.8 & 74.8 & 76.2 \\
\hline & Somewhat improved & 25.2 & 24.2 & 22.8 \\
\hline & Not much or worse & 0.0 & 1.0 & 1.0 \\
\hline \multirow{3}{*}{$\begin{array}{l}\text { Well-being of } \\
\text { community }\end{array}$} & Greatly improved & 82.1 & 85.0 & 83.3 \\
\hline & Somewhat improved & 17.4 & 14.5 & 16.0 \\
\hline & Not much or worse & 0.5 & 1.0 & 1.0 \\
\hline
\end{tabular}

Notes: All items were drawn from the twelve-month RESPECT survey (at end point of trial) except the final two questions, which were drawn from the twenty-four-month survey (one year after end of the trial).

overall, the study appears to be highly acceptable and valued by the study population. This is perhaps not surprising given the substantial amount of cash delivered by the project, but even control group enrollees (who did not receive cash beyond minimal inconvenience fees) responded quite positively about the trial. But could a trial such as this be brought to scale effectively and cost effectively?

The CCT programs for poverty alleviation have already been brought to scale in several different settings, and therefore have broken the credibility barrier by proving that it can be done. Of course, this has not eliminated concerns about whether incentive programs will be equally effective in other settings, particularly those where initial health infrastructural investments are very low, as in many countries in sub-Saharan Africa (Lagarde, Haines, and Palmer 2007).

Furthermore, the cost effectiveness of CCT programs when compared to traditional supply-side investments in health and education has not been sufficiently explored (Lagarde, Haines, and Palmer 2007). Cost analyses for STI-based incentive programs will need to account for not only the cash payments and monitoring infrastructure, but also STI-testing costs. Continued improvements in rapid diagnostic testing will help to ameliorate the latter costs over time, but they will still be central considerations. The RESPECT study design was not created for the purposes of scale-up. It will be important to experiment with alternative designs to test effectiveness of cheaper approaches. For example, one promising option could be to use a lottery to regularly choose random "winners" from a defined population (such as a subvillage), who would then be tested for STIs or HIV, and would only 
receive their lottery payout if negative. An ongoing project in Lesotho is further exploring variants of this idea; future studies of this type would be a high priority. However, these cost concerns must be balanced against the benefits of an effective behavioral intervention, and - again - too little is yet known to draw generalizable conclusions at this stage. Certainly the epidemiological context is highly relevant to this discussion, as the costs can be more easily justified in settings where the rate of disease transmission is very high. De Janvry and Sadoulet (2004) have raised concerns about inefficiencies in the design of CCT programs, pointing out that large-scale CCT programs fail to distinguish between those families who would have attended prenatal clinics and sent their children to school regardless of the incentive and those who require the incentive to induce the desired behavior. They conclude that CCT programs can be made more efficient if they do a better job of targeting the group that needs the incentive to be induced to alter their behaviors. This will pose a continuing challenge for STI incentive program design. Future cost-effectiveness and cost-benefit studies of CCTs in different target groups will be needed to inform these types of implementation decisions.

\section{References}

Askew, I., and M. Berer. 2003. "The Contribution of Sexual and Reproductive Health Services to the Fight Against HIV/AIDS: A Review." Reproductive Health Matters 11 (22): 51-73.

Baird, S., E. Chirwa, C. McIntosh, and B. Özler. 2010. "The Short-Term Impacts of a Schooling Conditional Cash Transfer Program on the Sexual Behavior of Young Women." Health Economics 19 (suppl.): 55-68.

Baird, S. R. Garfein, C. McIntosh, and B. Özler. 2012. "Effect of a Cash Transfer Programme for Schooling on Prevalence of HIV and Herpes Simplex Type 2 in Malawi: A Cluster Randomised Trial." Lancet 379 (9823): 1320-29.

Baird, S., C. McIntosh, and B. Özler. 2011. "Cash or Condition? Evidence from a Cash Transfer Experiment." Quarterly Journal of Economics 126(4): 1709-53.

Bertozzi, S., N. S. Padian, J. Wegbreit, L. M. DeMaria, B. Feldman, H. Gayle, J. Gold, R. Grant, and M. T. Isbell. 2006. "HIV/AIDS Prevention and Treatment." In Disease Control Priorities in Developing Countries, edited by Jamison, Breman, Meashem, and Mills. New York: World Bank.

Bertrand, J. R., K. O'Reilly, J. Denison, R. Anhang, and M. Sweat. 2006. "Systematic Review of the Effectiveness of Mass Communication Programs to Change HIV/AIDS-Related Behaviors in Developing Countries." Health Education and Research 21 (4): 567-97.

Cameron, J., K. M. Banko, and W. D. Pierce. 2001. "Pervasive Negative Effects of Rewards on Intrinsic Motivation: The Myth Continues." Behavioral Analyst 24 (1): $1-44$.

Coates, T. J., L. Richter, and C. Caceres. 2008. "Behavioural Strategies to Reduce HIV Transmission: How To Make Them Work Better.” Lancet 372:669-84. 
De Janvry, A., and E. Sadoulet. 2004. "Conditional Cash Transfer Programs: Are They Really Magic Bullets?" Working Paper, Department of Agriculture and Resource Economics, University of California, Berkeley.

Deren, S., R. Stephens, W. R. Davis, T. E. Feucht, and S. Tortu. 1994. "The Impact of Providing Incentives for Attendance at AIDS Prevention Sessions." Public Health Reports 109 (4): 548-54.

de Walque, D., W. H. Dow, R. Nathan, R. Abdul, F. Abilahi, E. Gong, Z. Isdahl, et al. 2012. "Incentivising Safe Sex: A Randomised Trial of Conditional Cash Transfers for HIV and Sexually Transmitted Infection Prevention in Rural Tanzania.” BMJ Open 2012 (2): e000747. doi: 10.1136/bmjopen-2011-000747.

Donatelle, R. J., S. L. Prows, D. Champeau, and D. Hudson. 2000. "Randomised Controlled Trial Using Social Support and Financial Incentives for High Risk Pregnant Smokers: Significant Other Supporter (SOS) Program." Tobacco Control 9:67-69.

Eiss, R., and R. Glass. 2007. "Bridging the Coverage Gap in Global Health." Journal of the American Medical Association 298 (16): 1940-42.

Emont, S., and K. Cummings. 1992. "Using a Low-Cost, Prize-Drawing Incentive to Improve Recruitment Rate at a Work-Site Smoking Cessation Clinic." Journal of Occupational Medicine 34:771-74.

Fernald, L. C. H., P. J. Gertler, and X. Hou. 2008. "Cash Component of Conditional Cash Transfer Program is Associated with Higher Body Mass Index and Blood Pressure in Adults." Journal of Nutrition 138:2250-57.

Fernald, L. C. H., P. J. Gertler, and L. M. Neufeld. 2008. "Role of Cash in Conditional Cash Transfer Programmes for Child Health, Growth, and Development: An Analysis of Mexico's Oportunidades." Lancet 371:827-37.

Fiszbein, A., and N. R. Schady. 2009. "Conditional Cash Transfers for Attacking Present and Future Poverty.” Policy Research Report, Washington, DC, World Bank.

Follick, M. J., J. I. Folwer, and R. A. Brown. 1984. "Attrition in Worksite WeightLoss Interventions: The Effects of an Incentive Procedure." Journal of Consultative Clinical Psychology 52:139-40.

Gertler, P. J. 2004. "Do Conditional Cash Transfers Improve Child Health? Evidence from PROGRESA's Control Randomized Experiment." American Economic Review 94 (2): 332-41.

Gertler, P. J., M. Shah, and S. M. Bertozzi. 2005. "Risky Business: The Market for Unprotected Commercial Sex.” Journal of Political Economy 113:518-50.

Haug, N., and J. Sorensen. 2006. "Contingency Management Interventions for HIVRelated Behaviors." Current HIVIAIDS Reports 3 (4): 154-59.

Higgins, S. T., A. J. Budney, W. K. Bickel, F. E. Foerg, R. Donham, and G. J. Badger. 1994. "Incentives Improve Outcomes in Outpatient Behavioral Treatment of Cocaine Dependence." Archives of General Psychiatry 51:568-76.

Higgins, S. T., S. H. Heil, R. Dantona, R. Donham, M. Matthews, and G. J. Badger. 2007. "Effects of Varying the Monetary Value of Voucher-Based Incentives on Abstinence Achieved during and following Treatment among Cocaine-Dependent Outpatients." Addiction 102 (2): 271-81.

Jeffery, R. W., W. M. Bjornson-Benson, B. S. Rosenthal, C. L. Kurth, and M. M. Dunn. 1984. "Effectiveness of Monetary Contracts with Two Repayment Schedules of Weight Reduction in Men and Women from Self-Referred and Population Samples.” Behavioral Therapy 15:273-79.

Jeffery, R. W., W. M. Gerber, B. S. Rosenthal, and R. A. Lindquist. 1983. "Monetary Contracts in Weight Control: The Effectiveness of Group and Individual Contracts of Varying Size." Journal of Consulting and Clinical Psychology 51:242-48. 
Jeffery, R. W., P. D. Thompson, and R. R. Wing. 1978. "Effects on Weight Reduction of Strong Monetary Contracts for Calorie Restriction or Weight Loss." Behavioral Research and Therapy 16 (5): 363-69.

Jewkes, R., M. Nduna, J. Levin, N. Jama, K. Dunkle, A. Puren, and N. Duwury. 2008. "Impact of Stepping Stones on Incidence of HIV and HSV-2 and Sexual Behaviour in Rural South Africa: Cluster Randomised Controlled Trial." BMJ 7:337a506.

John, L. K., G. Loewenstein, A. B. Troxel, L. Norton, J. E. Fassbender, and K. Volpp. 2011. "Financial Incentives for Extended Weight Loss: A Randomized, Controlled Trial." Journal of General Internal Medicine 26 (6): 621-26.

Joint United Nations Programme on HIV/AIDS (UNAIDS). 2010. Global Report: UNAIDS Report on the Global AIDS Epidemic 2010. Geneva: UNAIDS. http:// www.unaids.org/globalreport/Global_report.htm.

Kahneman, D., and A. Tversky. 1979. "Prospect Theory: An Analysis of Decision under Risk." Econometrica 47:263-91.

Kakwani, N., F. Soares, and H. Son. 2005. "Conditional Cash Transfers in African Countries." International Poverty Centre Working Paper no. 9, United Nations Development Programme.

Kamb, M. L., F. Rhodes, T. Hoxworth, J. Rogers, A. Lentz, C. Kent, R. MacGowen, and T. A. Peterman. 1998. "What About Money? Effect of Small Monetary Incentives on Enrollment, Retention, and Motivation to Change Behavior in an HIV/STD Prevention Counseling Intervention. The Project RESPECT Study Group.” Sexually Transmitted Infections 74:253-55.

Kane, R. L., P. E. Johnson, R. J. Town, and M. Butler. 2004. "A Structured Review of the Effect of Economic Incentives on Consumers' Preventive Behavior." American Journal of Preventive Medicine 27 (4): 327-52.

Kohler, H. P., and R. L. Thornton. 2011. "Conditional Cash Transfers and HIV/ AIDS Prevention: Unconditionally Promising?” World Bank Economic Review 26 (2): 165-90. doi: 10.1093/wber/lhr041.

Krishnan, S., D. Vohra, D. de Walque, C. Medlin, R. Nathan, and W. Dow. 2012. "Tanzanian Couples' Perspectives on Gender Equity, Relationship Power, and Intimate Partner Violence: Findings from the RESPECT Study." AIDS Research and Treatment 2012:1-9.

Lagarde, M., A. Haines, and N. Palmer. 2007. "Conditional Cash Transfers for Improving Uptake of Health Interventions in Low- and Middle-Income Countries: A Systematic Review.” Journal of American Medicine 298 (16): 1900-10.

Mauldon, J. G. 2003. "Providing Subsidies and Incentives for Norplant, Sterilization and Other Contraception: Allowing Economic Theory to Inform Ethical Analysis." Journal of Law, Medicine, and Ethics 31:351-64.

Medlin, C., and D. de Walque. 2008. "Potential Applications of Conditional Cash Transfers for Prevention of Sexually Transmitted Infections and HIV in SubSaharan Africa." Policy Research Working Paper no. 4673, Washington, DC, World Bank.

Nigenda, G., and L. M. Gonzalez-Robledo. 2005. "Lessons Offered by Latin American Cash Transfer Programmes, Mexico's Oportunidades and Nicaragua's SPN: Implications for African Countries." Working Paper, DFID Health Systems Resource Centre, Department for International Development. http://www.eldis .org/fulltext/verypoor/5_ningenda.pdf.

O'Donoghue, T., and M. Rabin. 2001. "Risky Behavior among Youths: Some Issues from Behavioral Economics" In Risky Behavior among Youths, edited by J. Gruber, 29-68. Chicago: University of Chicago Press. 
Padian, N. S., S. I. McCoy, S. S. Karim, N. Hasen, J. Kim, M. Bartos, K. Katabira, S. M. Bertozzi, B. Schwartländer, and M. S. Cohen. 2011. "HIV Prevention Transformed: The New Prevention Research Agenda." Lancet 378 (9787): 269-78.

Paul-Ebhohimhen, V., and A. Avenell. 2008. "Systematic Review of the Use of Financial Incentive in Treatments for Obesity and Overweight." Obesity Reviews 9 (4): 355-67.

Petry, N. M. 2000. "A Comprehensive Guide to the Application of Contingency Management Procedures in Clinical Settings." Drug and Alcohol Dependence 58:9-25.

Petry, N. M., B. Martin, and C. Finocche. 2001. "Contingency Management in Group Treatment: A Demonstration Project in an HIV Drop-In Center." Journal of Substance Abuse Treatment 21:89-96.

Petry, N. M., I. Petrakis, L. Trevisan, G. Wiredu, N. N. Boutros, B. Martin, and T. R. Kosten. 2001. "Contingency Management Interventions: From Research to Practice." American Journal of Psychiatry 158 (5): 694-702.

Philipson, T., and R. A. Posner. 1995. "The Microeconomics of the AIDS Epidemic in Africa." Population and Development Review 21 (4): 835-48.

Rawlings, L., and G. Rubio. 2005. "Evaluating the Impact of Conditional Cash Transfer Programs." World Bank Research Observer 20 (1): 29-55.

Rawson, R. A., A. Huber, M. McCann, S. Shoptaw, D. Farabee, C. Reiber, and W. Ling. 2002. "A Comparison of Contingency Management and CognitiveBehavioral Approaches during Methadone Maintenance Treatment for Cocaine Dependence." Archives of General Psychiatry 59 (9): 817-24.

Robinson, J., and E. Yeh. 2011. "Transactional Sex as a Response to Risk in Western Kenya." American Economic Journal: Applied Economics 3 (1): 35-64.

Rosen, M. I., K. Dieckhaus, T. J. McMahon, B. Valdes, N. M. Petry, J. Cramer, and B. Rounsaville. 2007. "Improved Adherence with Contingency Management." AIDS Patient Care STDS 21 (1): 30-40.

Schady, N., and J. Rosero. 2007. "Are Cash Transfers Made to Women Spent Like Other Sources of Income?" World Bank Policy Research Working Paper no. 4282, Washington, DC, World Bank.

Schubert, B., and R. Slater. 2006. "Social Cash Transfers in Low Income African Countries: Conditional or Unconditional?" Development Policy Review 24 (5): 571-78.

Schuring E. 2005. "Conditional Cash Transfers: A New Perspective for Madagascar?" A World Bank Report, Washington, DC, World Bank.

Silverman, K., S. T. Higgins, R. K. Brooner, I. D. Montoya, E. J. Cone, C. R. Schuster, and K. L. Preston. 1996. "Sustained Cocaine Abstinence in MethodoneMaintenance Patients through Voucher-Based Reinforcement Therapy." Archives of General Psychiatry 53:409-15.

Sindelar, J., B. Elbel, and N. M. Petry. 2007. "What Do We Get For Our Money? Cost Effectiveness of Adding Contingency Management." Addiction 102 (2): 309-16.

Sridhar, D., and A. Duffield. 2006. "A Review of the Impact of Cash Transfer Programmes on Child Nutritional Status and Some Implications for Save the Children UK Programmes." Save the Children. http://www.savethechildren.org.uk/sites /default/files/docs/cash_transfer_prog_nutrition_1.pdf.

Stitzer, M. 2006. "Contingency Management and the Addictions." Addiction 101:1536-37.

Stitzer, M., and G. E. Bigelow. 1983. "Contingent Payment for Carbon Monoxide Reduction: Effects of Pay Amount." Behavioral Therapy 14:647-56. 
Stitzer, M., and N. Petry. 2006. "Contingency Management for Treatment of Substance Abuse.” Annual Review of Clinical Psychology 2:411-34.

Thaler, R., and C. Sunstein. 2008. Nudge: Improving Decisions about Health, Wealth, and Happiness. New Haven, CT: Yale University Press.

Thornton, R. 2008. "The Demand for and Impact of Learning HIV Status." American Economic Review 98:1829-63.

Vandrey, R., G. E. Bigelow, and M. L. Stitzer. 2007. "Contingency Management in Cocaine Abusers: A Dose-Effect Comparison of Goods-Based versus CashBased Incentives." Experimental Clinical Psychopharmacology 15 (4): 338-43.

Volpp, K., L. John, A. B. Troxel, L. Norton, J. Fassbender, and G. Lowenstein. 2008. "Financial Incentive-Based Approaches for Weight Loss: A Randomized Trial." Journal of the American Medical Association 300 (22): 2631-37.

Volpp, K., A. B. Troxel, M. V. Pauly, H. Glick, A. Puig, D. Asch, R. Galvin, J. Zhu, F. Wan, J. DeGuzman, E. Corbett, J. Weiner, and J. Audrain-McGovern. 2009. "A Randomized Controlled Trial of Financial Incentives for Smoking Cessation." New England Journal of Medicine 360:699-709.

Weeden, D., A. Bennett, D. Lauro, and M. Viravaidya. 1986. "An Incentives Program to Increase Contraceptive Prevalence in Rural Thailand." International Family Planning Perspectives 12 (1): 11-16.

Windsor, R. A., J. B. Lowe, and E. E. Bartlett. 1988. "The Effectiveness of a Worksite Self-Help Smoking Cessation Program: A Randomized Trial.” Journal of Behavioral Medicine 11:407-21. 